\title{
The Lateral Ventricles: A Detailed Review of Anatomy, Development, and Anatomic Variations
}

\author{
(D)C.L. Scelsi, (D)T.A. Rahim, (D).A. Morris, (D) G.J. Kramer, (D)B.C. Gilbert, and (D)S.E. Forseen
}

\begin{abstract}
SUMMARY: The cerebral ventricles have been studied since the fourth century $B C$ and were originally thought to harbor the soul and higher executive functions. During the infancy of neuroradiology, alterations to the ventricular shape and position on pneumoencephalography and ventriculography were signs of mass effect or volume loss. However, in the current era of high-resolution cross-sectional imaging, variation in ventricular anatomy is more easily detectable and its clinical significance is still being investigated. Interpreting radiologists must be aware of anatomic variations of the ventricular system to prevent mistaking normal variants for pathology. We will review of the anatomy and development of the lateral ventricles and discuss several ventricular variations.
\end{abstract}

$\mathbf{T}$ he cerebral ventricles were the center of attention among philosophers, priests, anatomists, and physicians as far back as Aristotle in the fourth century BC. ${ }^{1}$ They were originally thought to harbor the soul and "vital" spirits responsible for higher functions. After the influence of Christianity and the Renaissance, the ventricles were conceptualized as 3 cavities where common sense, creative imagination, and memory were individually allocated. It was not until the 16th century that anatomists Andreas Vesalius and Constanzo Varolio identified ventricles as being filled with $\mathrm{CSF}^{2}$

Before the era of cross-sectional imaging, when ventriculography and pneumoencephalography were the only modalities available, variations in ventricular morphology were used as signs of parenchymal volume loss or mass effect. ${ }^{3,4}$ Currently, asymmetries and anatomic variations are frequently identified and accepted as normal variations. Although they are not frequently a diagnostic dilemma, imaging interpreters must be aware of these anatomic variants to prevent mistaking them for pathology. In this review, we discuss normal anatomy, ventricular development, and anatomic variations of the lateral ventricles along with a deep look into the investigation of these entities. Pathologic states (ie, hydrocephalus, degenerative disease, traumatic encephalopathy, and so forth) can affect

Received November 12, 2019; accepted after revision January 6, 2020.

From the Departments of Radiology (C.L.S., T.A.R., J.A.M., G.J.K.) and Neuroradiology (B.C.G., S.E.F.), Medical College of Georgia, Augusta, Georgia.

Please address correspondence to Chris L. Scelsi, DO, 1120 15th St, Augusta, GA, 30912; e-mail: cscelsi@augusta.edu

- Indicates open access to non-subscribers at www.ajnr.org

http://dx.doi.org/10.3174/ajnr.A6456 ventricular size and morphology but have been studied extensively and will be left out of this review.

\section{ANATOMY \\ Lateral Ventricles}

The lateral ventricles are paired C-shaped structures comprising a body and atrium along with 3 projections into the frontal, temporal, and occipital lobes, termed "horns." The lateral ventricles communicate with the third ventricle through the interventricular foramina of Monro. ${ }^{5}$ Each lateral ventricle has an estimated capacity of 7-10 mL. ${ }^{6}$

The frontal horn (Fig 1) extends anteriorly from the foramina of Monro and communicates with the body of the lateral ventricles posteriorly. The anterior wall and roof are formed by the genu of the corpus callosum, and the floor is formed by the rostrum. The head of the caudate nucleus forms the lateral wall. The columns of the fornix form the inferior portion of the medial wall. $^{6-8}$

The body of the lateral ventricle communicates with the atrium posteriorly from the foramina of Monro to the corpus callosum and psalterium of the fornix, also called the hippocampal commissure. The roof is formed by the body of the corpus callosum, and the floor is formed by the thalamus. The septum pellucidum and body of the fornix form the superior and inferomedial walls, respectively. The lateral wall is formed by the caudate nucleus and thalamus. In the groove between the caudate nucleus and thalamus along the lateral wall sits the stria terminalis, a main outlet pathway of the amygdala and the location of the thalamostriate vein. ${ }^{9}$

The atrium (Fig 2) is a triangular cavity that communicates with the body, temporal horn, and occipital horn. The body and 


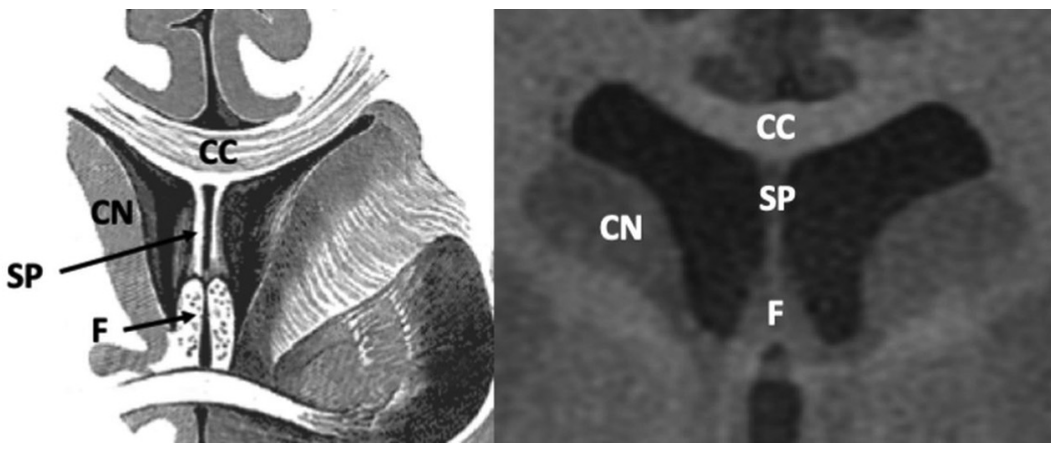

FIG 1. Anatomy of the frontal horns of the lateral ventricles. Coronal T1-weighted MR image from a healthy 22-year-old man. CN indicates caudate nucleus; CC, body of the corpus callosum; $\mathrm{F}$, columns of the fornices; SP, septum pellucidum. Illustration adapted with permission from Gray. $^{64}$

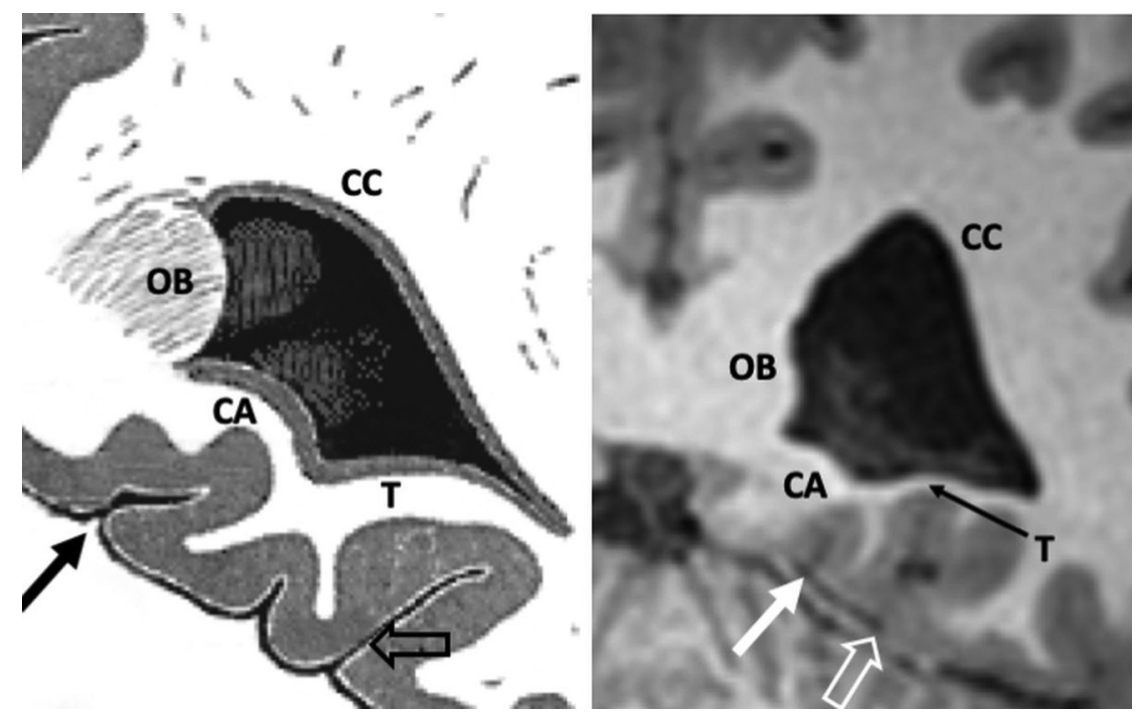

FIG 2. Anatomy of the atrium of the left lateral ventricle. Coronal Tl-weighted MR image from a healthy 21-year-old woman. OB indicates occipital bulb containing fibers of forceps major; CA, calcar avis; T, collateral trigone; CC, tapetum of the corpus callosum; solid arrow, calcarine sulcus; open arrow, collateral sulcus. Illustration adapted with permission from Gray. ${ }^{65}$ the thalamus, tail of the caudate nucleus, and tapetum. The striothalamic sulcus separates the caudate tail and thalamus. The tapetum also runs inferiorly to comprise the lateral wall and separates the lateral wall from the optic radiations. The choroidal fissure runs along the medial wall. ${ }^{12}$

The occipital horn curves posteriorly and medially from the atrium and varies in size. The tapetum forms the roof and lateral wall and separates it from the optic radiations. ${ }^{7,9,11}$ The collateral trigone forms the floor. Similar to the atrium, the bulb of the corpus callosum and calcar avis form the medial wall. ${ }^{9}$

\section{Choroid Plexus and Choroidal \\ Fissure}

The choroid plexus is present within the lateral, third, and fourth ventricles and is the primary source of CSF, producing approximately $500 \mathrm{~mL}$ per day. ${ }^{13,14}$ Within the lateral ventricles, the choroid plexus runs along a cleft between the fornix and thalamus called the choroidal fissure. The choroidal fissure forms a C-shape extending from the foramina of Monro to its inferior terminal point, which is termed the "inferior choroidal point." 9,15 Within the atria, there is a prominent triangular tuft called the glomus. ${ }^{15}$ The tela choroidea is an invagination of the pia mater and ependyma, which gives rise to the choroid plexus within the choroidal fissure and along the roof of the third ventricle. ${ }^{9,16}$

splenium of the corpus callosum form the roof. The tapetum, which is a sheetlike bundle of decussating fibers in the splenium of the corpus callosum, arches over the atrium and forms the roof. The tapetum continues laterally and comprises the lateral wall and the caudate nucleus. The floor is created by the collateral trigone, a continuation of the collateral eminence formed by the collateral sulcus. The contour of the medial wall is formed by the calcar avis and bulb of the corpus callosum, which is a bulging created by the forceps major. ${ }^{5,9}$ The calcar avis was previously known as the hippocampus minor and represents an indentation formed by the calcarine fissure. ${ }^{10}$ When prominent, the calcar avis can mimic hemorrhage on cranial sonography. ${ }^{11}$

The temporal horn is the longest and largest horn, extending anteriorly from the atrium below the thalamus and terminating at the amygdala. The collateral eminence and hippocampus form the floor, which is separated from the hippocampus by a thin layer of white matter called the alveus. ${ }^{11,12}$ The roof is created by
The choroidal fissure is an important neurosurgical structure because it opens up access to the basal cisterns and to structures that would be otherwise inaccessible through an extracerebral route. ${ }^{9}$ Recently, excess CSF has been shown to pass through the inferior choroidal point in patients with idiopathic normal pressure hydrocephalus. Its anatomic relationship may explain disproportionate enlargement of the basal cisterns and Sylvian fissures in patients with idiopathic normal pressure hydrocephalus. ${ }^{17}$

\section{DEVELOPMENT}

After closure of the neural tube during the fourth week of gestation, the lateral ventricles begin forming from the 2 outpouchings of the telencephalon, a derivative of the prosencephalon. ${ }^{18,19}$ The lateral walls of the telencephalon evaginate, and there is rapid growth of the medial basal portion of the cerebral hemispheres called the corpus striatum, which ultimately gives rise to the basal ganglia. This rapid growth shapes the floor and narrows the foramina of Monro (Fig 3). ${ }^{18,20-22}$ 


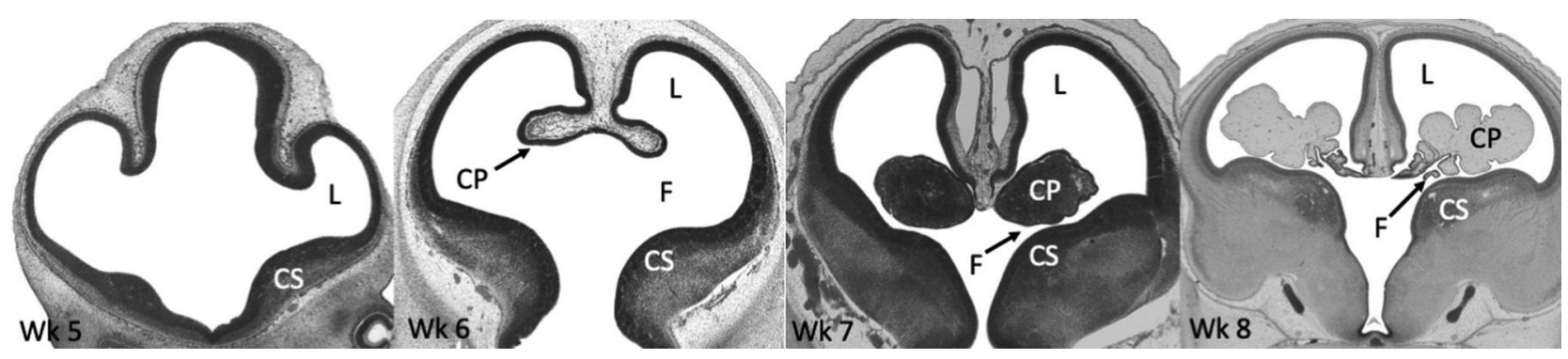

FIG 3. Histologic sections of the telencephalon in the developing embryo from weeks 5 to 8 . The lateral ventricles (L) arise as outpouchings from the telencephalon. Rapid growth of the corpus striatum (CS) shapes the floor of the lateral ventricles and narrows the foramina of Monro (F). The primitive choroid plexus (CP) comprises a large portion of the ventricular cavity by the eighth week. Also note that the lateral ventricles occupy a large majority of the cerebral hemisphere at 8 weeks. Images courtesy of Dr John Cork, PhD, Department of Cell Biology and Anatomy at Louisiana State University Health Sciences Center and the Virtual Human Embryo Project. Images used were the following: Carnegie Stage 17, section 410; Carnegie stage 18, section 302; Carnegie stage 20, section 131; Carnegie stage 23, section 50. https://www.ehd.org/virtual-humanembryo.

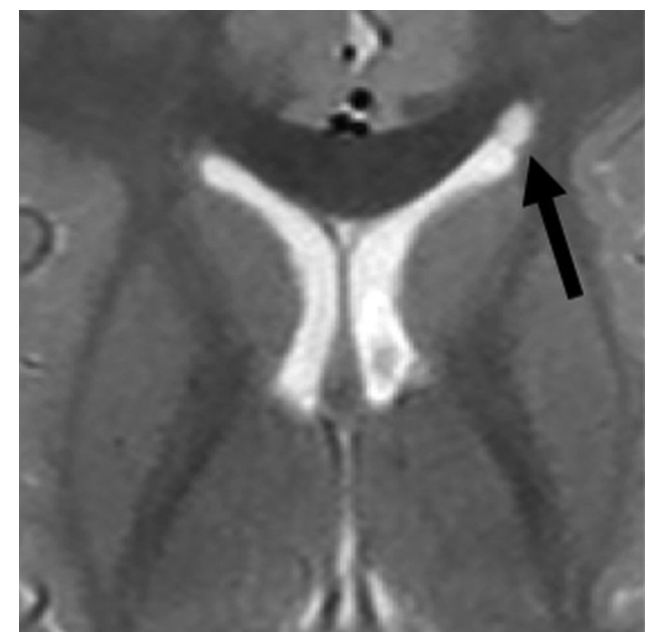

FIG 4. Coarctation of the frontal horn. Axial T2-weighted MR image from a 3-year-old boy showing coarctation of the left frontal horn with connatal cyst formation (black arrow).

During the sixth week, the foramina of Monro begins to narrow (Fig 3), and the choroidal fissure forms. ${ }^{20,21}$ By the eighth week, further growth of the corpus striatum forms the C-shaped appearance of the lateral ventricles. The frontal and temporal horns are now well-defined, and the choroid plexus nearly fills the entirety of the lateral ventricles (Fig 3). ${ }^{21}$

At the end of the first trimester, the lateral ventricles continue to expand rapidly, occupying a large majority of the cerebral hemispheres, outpacing parenchymal growth. ${ }^{23}$ Transient occlusion of the central canal of the spinal cord may facilitate this rapid increase in ventricle size. ${ }^{24}$ Parenchymal growth hastens during the second trimester, and by 21 weeks, the frontal, temporal, and occipital horns are well-defined. By 31 weeks, the lateral ventricles resemble the adultlike appearance. ${ }^{25,26}$

\section{ANATOMIC VARIANTS Coarctation}

Coarctation (Fig 4) refers to the apposition or fusion of 2 ventricular walls, resulting in partial or complete obliteration of the lumen. ${ }^{27}$ When focal, coarctation can isolate a portion of the ventricle, creating multiple small rosettes or an ependymallined cyst, commonly referred to as a connatal cyst (Fig 4). ${ }^{28,29}$ The incidence of unilateral or bilateral frontal horn coarctation has been reported to be between $0.38 \%$ and $6.0 \%$, with a majority of studies reporting incidences below $1 \% .{ }^{30-32}$ Coarctation of the occipital horns is much more common, with a reported incidence of $21.3 \%$. $^{33}$

Coarctation is thought to occur at sites where opposing walls are in close proximity as is in the case with the ventricular horns, but it also has been described as occurring in the body. ${ }^{28,31,33}$ The exact mechanism of ventricular coarctation is currently unknown. Bates and Netsky ${ }^{28}$ described intermingling of subependymal glial cells at sites where the ventricular wall lacks ependyma. Davidoff ${ }^{27}$ reported similar findings in cases of congenital aqueductal stenosis. ${ }^{34}$ No histologic evidence of inflammation or gliosis has been associated with coarctation, suggesting that it is developmental in nature. $^{27,28}$

Ventricular coarctation is accepted as benign and is associated with normal neurodevelopmental outcomes when occurring in isolation. ${ }^{29,35}$ When identified in neonates, coarctation often resolves spontaneously by 2 months of age. ${ }^{36}$ However, it can commonly be mistaken for similar-appearing subependymal cysts or periventricular leukomalacia, which can be associated with less favorable outcomes. ${ }^{36-38}$ Identifying the location of the cyst with respect to the superolateral angles of the lateral ventricles, which are formed by the most superior and lateral margins, is a key distinguishing feature. Connatal cysts (Fig $5 A$ ) occur anterior to the foramina of Monro and at the level of the angles. Periventricular leukomalacia (Fig 5B) should be considered when cyst formation is located above the angles, and subependymal cysts (Fig $5 C$ ) should be considered when it is located below the angles and at the caudothalamic groove. ${ }^{11,39,40}$

\section{Asymmetric Size and Morphology}

Size asymmetry between the lateral ventricles (Fig 6) occurs in $5 \%-12 \%$ of healthy individuals. ${ }^{41}$ In healthy patients, some studies have found that either the right or left lateral ventricle 


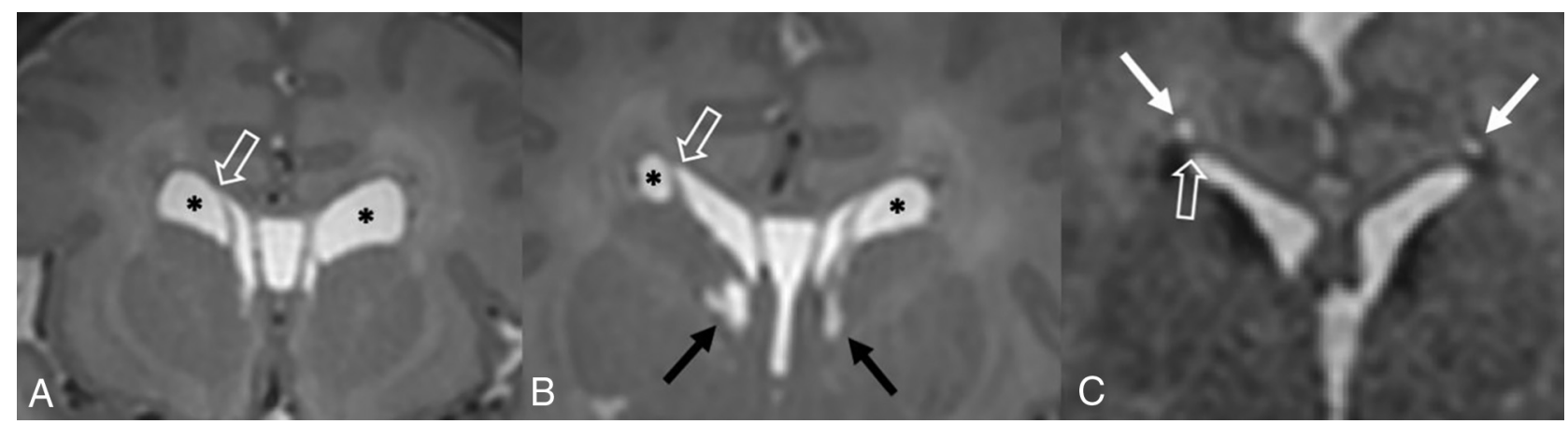

FIG 5. Periventricular cysts. A, Coronal T2-weighted MR image from a 1-week-old girl with a history of germinal matrix hemorrhage demonstrating coarctation of the bilateral frontal horns with connatal cyst formation (asterisks). Note that these cysts are at the level of the superolateral angles of the lateral ventricle (open arrow). B, Coronal T2-weighted MR image from the same patient demonstrating subependymal cysts (black arrows) located near the caudothalamic groove below the level of the superolateral angles (open arrow). Additional connatal cysts are present (asterisks). C, Coronal T2-weighted MR image from a 1-month-old boy with a history of germinal matrix hemorrhage and peripartum hypoxia demonstrating small bilateral periventricular cysts (white arrows) located above the level of the superolateral angles (open arrow). This appearance is consistent with cystic periventricular leukomalacia.

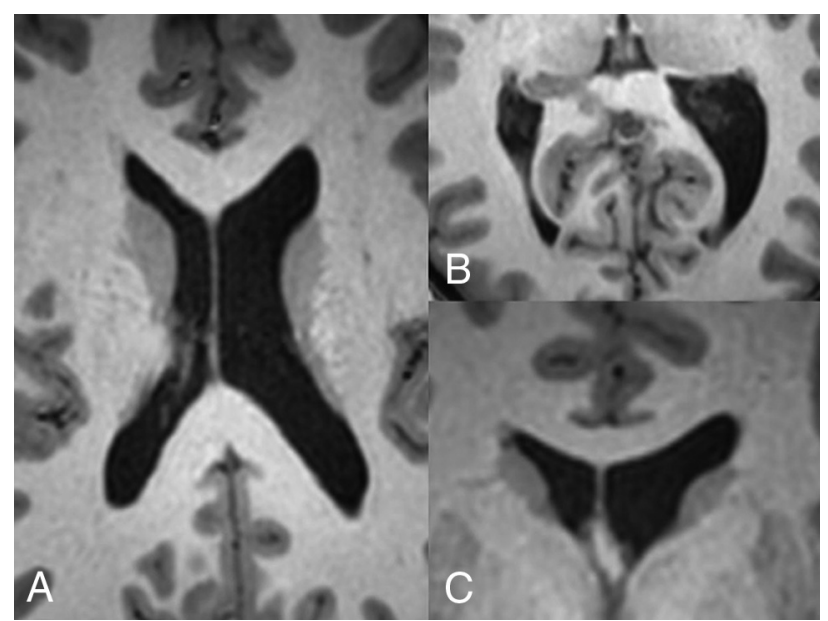

FIG 6. Variations in lateral ventricular size and shape in a healthy 16-year-old girl. Axial Tl-weighted MR images through the bodies of the lateral ventricles $(A)$ and occipital horns $(B)$ demonstrate a larger left lateral ventricle. Note the differences in morphology of the occipital horns. C, Coronal T1-weighted MR image through the frontal horns demonstrates relative enlargement of the left lateral ventricle.

was consistently larger than the other, ${ }^{26,42-47}$ while other studies have reported no significant difference in size between the two. ${ }^{48,49}$ The association between lateral ventricle asymmetry, handedness, and sex is also controversial, with multiple studies showing a significant difference in lateral ventricle size in right- versus left-handed individuals and males versus females. ${ }^{45,49,50}$ Other studies have shown no significant difference in these populations. ${ }^{41,43,47,48}$

The shape of the lateral ventricles has also been investigated extensively, with multiple studies classifying various lateral ventricular morphologies and rotational differences. ${ }^{42,51-}$ 53 The occipital horn of the lateral ventricle seems to be the most inconsistent portion, which can range from being completely absent to being present in variable lengths (Fig $6 B){ }^{33,48,54}$ The temporal horn, especially the anterior tip, is also variable in shape but to a lesser extent compared with the occipital horn. ${ }^{55}$

The clinical significance of varying lateral ventricular asymmetries is currently controversial. On the basis of the association of ventricular morphologic abnormalities due to underlying white matter damage, it has been suggested that mild ventricular asymmetries may be a sign of subtle white matter or deep gray matter abnormalities that may not be seen on imaging. Paquette et $\mathrm{al}^{51}$ proposed that differences in the left lateral ventricle in preterm neonates may be related to subcortical white matter alterations, suggesting subcortical vulnerability to preterm birth. ${ }^{42}$ Sadan et $\mathrm{al}^{56}$ studied fetuses with normal-sized-but-asymmetric ventricles (defined as width of $<10 \mathrm{~mm}$ and a difference in width of $>2 \mathrm{~mm}$ ) and demonstrated increased behavioral abnormalities in these children.

To our knowledge, no definitive large-scale investigation of variations in lateral ventricle morphology and long-term neurologic outcome has been performed. Therefore, it is generally accepted that small volumetric or morphologic differences between normal-sized lateral ventricles are likely of no clinical significance and have no effect on long-term neurode-

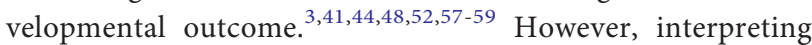
radiologists should evaluate adjacent parenchymal disease, an intraventricular lesion, or obstruction at the foramina of Monro before dismissing ventricular asymmetry as a anormal variant (Fig 7). ${ }^{60}$

\section{Cavum Septi Pellucidi, Cavum Vergae, and Cavum Veli Interpositi}

The septum pellucidum forms the medial walls of the lateral ventricles and consists of 2 thin laminae, which normally fuse shortly after birth. If the laminae fail to fuse, the potential space can expand with CSF, termed "cavum septi pellucidi." If there is an extension posterior to a vertical plane created by the columns of the fornix, the term cavum vergae (Fig 8) is used. ${ }^{6,39}$ The clinical significance of cavum septi pellucidi and cavum vergae is unknown, and they are considered a normal variant. ${ }^{39}$ However, studies have suggested that their presence 


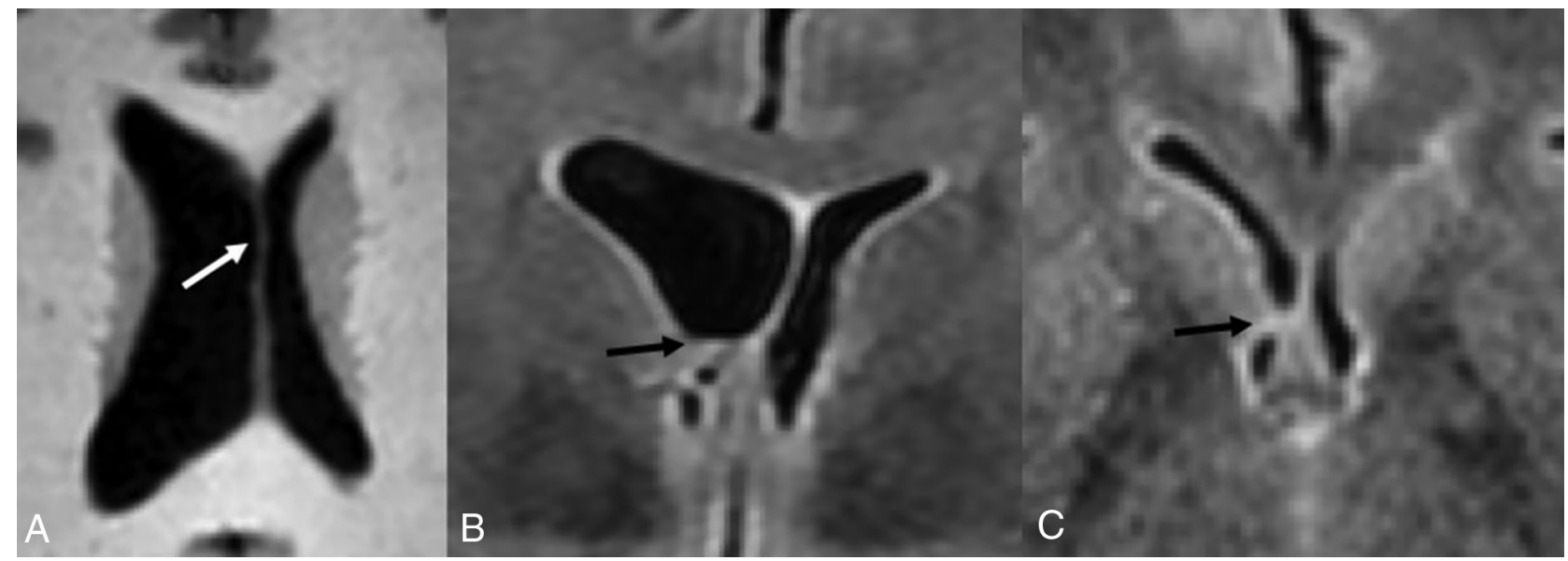

FIG 7. Lateral ventricular asymmetry in a 56-year-old woman referred from a separate institution for the management of a suspected intraventricular mass. A, Axial T1-weighted MR images demonstrate asymmetric enlargement of the right lateral ventricle. There is mild bulging of the septum pellucidum (white arrow), which prompted careful evaluation of the lateral ventricular outflow. Coronal (B) and Axial (C) T2-weighted FLAIR images show no intraventricular mass but rather coaptation of the ependyma covering the caudate nucleus and fornix (black arrow). These imaging findings causes partial outflow obstruction and unilateral hydrocephalus. This remained stable on multiple subsequent follow-up MRIs and was favored to represent coarctation versus scar.

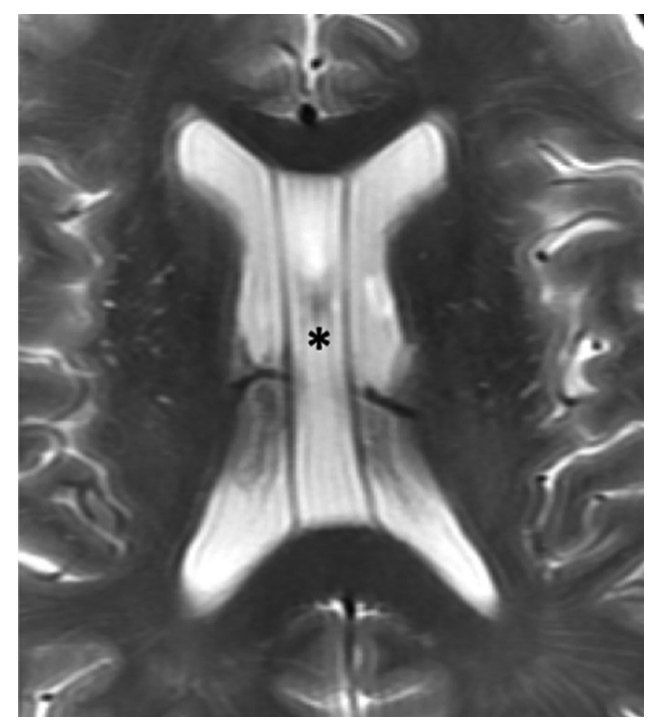

FIG 8. Cavum septi pellucidi and vergae. Axial T2-weighted MR image of a 67-year-old man demonstrating expansion of the cavum septi, consistent with cavum septi pellucidi (asterisk). There is extension posterior to the vertical plane of the columns of the fornix (not shown here) consistent with coexisting cavum vergae.

is associated with cognitive dysfunction in patients with prior head trauma. ${ }^{61}$ Also, the size and frequency of cavum septi pellucidi and cavum vergae were greater in patients with schizophrenia, alcoholism, and prior head trauma. ${ }^{62}$ The cavum septi pellucidi is a normal finding in fetuses between 18 and 37 weeks of gestation, and its absence is associated with multiple significant CNS abnormalities. ${ }^{63}$

The cavum veli interpositi results from expansion of the cistern of the velum interpositum, which is located above the third ventricle and below the columns of the fornices. When large, it may mimic a cyst. The cavum veli interpositi is accepted as a normal variant, and no association with cognitive dysfunction or neuropsychiatric disorders has been reported. $^{39}$

\section{Choroid Plexus Cysts}

Choroid plexus cysts may be acquired or congenital. The acquired cysts are common in adults and are formed by accumulation of xanthogranulomatous debris; hence, these are more frequently referred to as xanthogranulomas. Xanthogranulomas are usually bilateral and demonstrate $\mathrm{T} 1$ and $\mathrm{T} 2$ signal characteristics similar to those of CSF but may not be completely suppressed on FLAIR. They are also typically hyperintense on DWI, with isointense signal on ADC (Fig 9A).,

Choroid plexus cysts are typically found incidentally, mainly in the glomera, and they are usually asymptomatic. In the antenatal period, choroid plexus cysts may be associated with chromosomal abnormalities when large or when present with other CNS abnormalities. ${ }^{39}$

An important differential consideration is a choroidal metastasis, which may mimic xanthogranulomas, especially when cystic. However, the typical bilateral occurrence of xanthogranulomas and lack of internal enhancement can help differentiate the two (Fig 9B). An ependymal cyst is also a differential consideration, but these typically more closely follow CSF signal. They also arise outside the choroid plexus and displace the glomera, unlike xanthogranulomas. ${ }^{5}$

\section{CONCLUSIONS}

Isolated anatomic variations of the lateral ventricles are very common in healthy individuals. In this article, we describe several anatomic variants of the lateral ventricles and review multiple studies of these entities. We also review the anatomy and embryology of the lateral ventricles. These variations are often mentally noted while interpreting studies, and because they are generally accepted as normal and of no clinical significance to the patient, they are infrequently mentioned in radiology reports. Although 


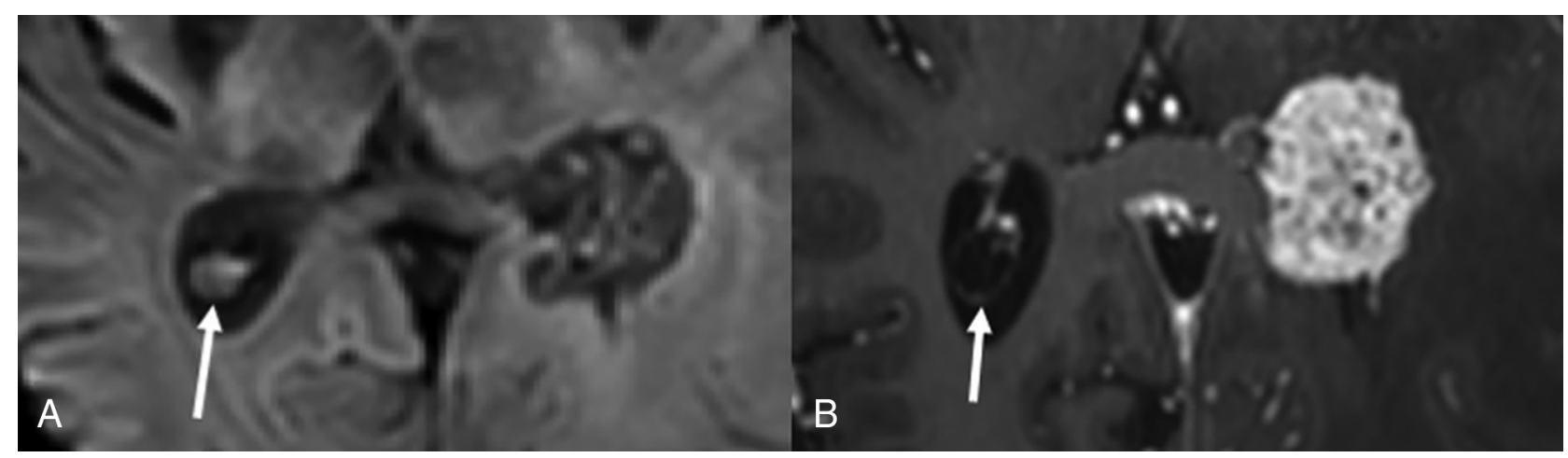

FIG 9. Xanthrogranuloma and choroid plexus metastasis. Axial DWI (A) and postgadolinium T1-weighted (B) MR images of a 56-year-old woman with metastatic renal cell carcinoma. Images demonstrate a cystic lesion centered within the right choroid plexus glomus, which demonstrates increased DWI signal but no central enhancement (arrow), consistent with a xanthogranuloma. This finding is in contrast to the solidly-enhancing lesion centered within the left glomus, consistent with a hypervascular metastasis.

identification of these is rarely a diagnostic dilemma, interpreting radiologists should be aware of these entities because some cases may mimic pathology.

\section{REFERENCES}

1. Engelhardt E. Cerebral localization of the mind and higher functions: the beginnings. Dement Neuropsychol 2018;12:321-25 CrossRef Medline

2. Schiller F. The cerebral ventricles: from soul to sink. Arch Neurol 1997;54:1158-62 CrossRef Medline

3. Shapiro R, Galloway SJ, Shapiro MD. Minimal asymmetry of the brain: a normal variant. AJR Am J Roentgenol 1986;147:753-56 CrossRef Medline

4. Hoeffner EG, Mukherji SK, Srinivasan A, et al. Neuroradiology back to the future: brain imaging. AJNR Am J Neuroradiol 2012;33:5-11 CrossRef Medline

5. Osborn AG, Hedlund GL, Salzman KL. Osborn's Brain. Philadelphia: Elsevier; 2018:1119-25

6. Stratchko L, Filatova I, Agarwal A, et al. The ventricular system of the brain: anatomy and normal variations. Semin Ultrasound CT MR 2016;37:72-83 CrossRef Medline

7. Snell RS. Clinical Neuroanatomy. Baltimore: Lippincott Williams \& Wilkins; 2001:444-56

8. Mortazavi MM, Adeeb N, Griessenauer CJ, et al. The ventricular system of the brain: a comprehensive review of its history, anatomy, histology, embryology and surgical considerations. Childs Nerv Syst 2014;30:19-35 CrossRef Medline

9. Rhoton AL. The lateral and third ventricles. Neurosurgery 2002;51: S207-71 Medline

10. Owen CM, Howard A, Binder DK. Hippocampus minor, calcar avis and the Huxley-Owen debate. Neurosurgery 2009;65:1098-1105 CrossRef Medline

11. Enríquez G, Correa F, Lucaya J, et al. Potential pitfalls in cranial sonography. Pediatr Radiol 2003;33:110-17 CrossRef Medline

12. Singh I. Textbook of Human Neuroanatomy. New Delhi: Jaypee Brothers Medical Publishers; 2018:228-38

13. Mortazavi MM, Griessenauer CJ, Adeeb N, et al. The choroid plexus: a comprehensive review of its history, anatomy, function, histology, embryology and surgical considerations. Childs Nerv Syst 2014; 30:205-14 CrossRef Medline

14. Brinker T, Stopa E, Morrison J, et al. A new look at cerebrospinal fluid circulation. Fluids Barriers CNS 2014;11:10 CrossRef Medline

15. Holodny AI, George AE, Golomb J, et al. The perihippocampal fissures: normal anatomy and disease states. Radiographics 1998;18: 653-65 CrossRef Medline
16. Zagorska-Swiezy K, Litwin JA, Gorczyca J, et al. Arterial supply and venous drainage of the choroid plexus of the human lateral ventricle in the prenatal period as revealed by vascular corrosion casts and SEM. Folia Morphol (Warsz) 2008;67:209-13 Medline

17. Yamada S, Ishikawa M, Iwamuro Y, et al. Choroidal fissure acts as an overflow device in cerebrospinal fluid drainage: morphological comparison between idiopathic and secondary normal-pressure hydrocephalus. Sci Rep 2016;6:39070 CrossRef Medline

18. Sadler TW. Langman's Medical Embryology. Baltimore: Lippincott Williams \& Wilkins; 2012:287-308

19. O’Rahilly R, Müller F. Human Embryology \&Teratology. New York: Wiley-Liss; 2001: 405-29

20. Moore KL, Persaud T. The Developing Human: Clinically Oriented Embryology. Philadelphia: W.B. Saunders; 1998:451-77

21. O'Rahilly R, Müller F. Ventricular system and choroid plexuses of the human brain during the embryonic period proper. Am J Anat 1990;189:285-302 CrossRef Medline

22. Yamada S, Samtani RR, Lee ES, et al. Developmental atlas of the early first trimester human embryo. Dev Dyn 2010;239:1585-95 CrossRef Medline

23. Lowery LA, Sive H. Totally tubular: the mystery behind function and origin of the brain ventricular system. Bioessays 2009;31:44658 CrossRef Medline

24. Desmond ME. Description of the occlusion of the spinal cord lumen in early human embryos. Anat Rec 1982;204:89-93 CrossRef Medline

25. Kinoshita Y, Okudera T, Tsuru E, et al. Volumetric analysis of the germinal matrix and lateral ventricles performed using MR images of postmortem fetuses. AJNR Am J Neuroradiol 2001;22:382-88 Medline

26. Li Z, Xu F, Zhang Z, et al. Morphologic evolution and coordinated development of the fetal lateral ventricles in the second and third trimesters. AJNR Am J Neuroradiol 2019;40:718-25 CrossRef Medline

27. Davidoff LM. Coarctation of the walls of the lateral angles of the lateral cerebral ventricles. $J$ Neurosurg 1946;3:250-56 CrossRef Medline

28. Bates JI, Netsky MG. Developmental anomalies of the horns of the lateral ventricles. J Neuropathol Exp Neurol 1955;14:316-25 CrossRef Medline

29. Cooper S, Bar-Yosef O, Berkenstadt M, et al. Prenatal evaluation, imaging features, and neurodevelopmental outcome of prenatally diagnosed periventricular pseudocysts. AJNR Am J Neuroradiol 2016;37:2382-88 CrossRef Medline

30. Chang CL, Chiu NC, Ho CS, et al. Frontal horn cysts in normal neonates. Brain Dev 2006;28:426-30 CrossRef Medline

31. Sener RN. MRI and asymptomatic coarctation of the frontal lateral ventricle horn. J Neuroradiol 1997;24:163-67 Medline

AJNR Am J Neuroradiol 41:566-72 Apr 2020 www.ajnr.org 
32. Pal BR, Preston PR, Morgan MEI, et al. Frontal horn thin walled cysts in preterm neonates are benign. Arch Dis Child Fetal Neonatal Ed 2001;85:F187-93 CrossRef Medline

33. Hori A, Bardosi A, Tsuboi K, et al. Accessory cerebral ventricle of the occipital lobe: morphogenesis and clinical and pathological appearance. J Neurosurg 1984;61:767-71 CrossRef Medline

34. Beckett RS, Netsky MG, Zimmerman HM. Developmental stenosis of the aqueduct of Sylvius. Am J Pathol 1950;26:755-87 Medline

35. Unger S, Salem S, Wylie L, et al. Newborn frontal horn cysts: cause for concern? J Perinatol 2011;31:98-103 CrossRef Medline

36. Sun RL, Tekes A, Golden WC, et al. Connatal cyst in a preterm twin infant with maternal comorbidities. Pediatr Neurol 2014;51:444-47 CrossRef Medline

37. Rosenfeld DL, Schonfeld SM, Underberg-Davis S. Coarctation of the lateral ventricles: an alternative explanation for subependymal pseudocysts. Pediatr Radiol 1997;27:895-97 CrossRef Medline

38. Lu JH, Emons D, Kowalewski S. Connatal periventricular pseudocysts in the neonate. Pediatr Radiol 1992;22:55-58 CrossRef Medline

39. Epelman M, Daneman A, Blaser S, et al. Differential diagnosis of intracranial cystic lesions at head US: correlation with CT and MR imaging. Radiographics 2006;26:173-96 CrossRef Medline

40. Fickenscher K, Bailey Z, Saettele M, et al. Pediatric cranial ultrasound: techniques, variants and pitfalls. In: Bright $\mathrm{P}$, ed. Neuroimaging: Methods. London: IntechOpen; 2012:217-32

41. Kiroğlu Y, Karabulut N, Oncel C, et al. Cerebral lateral ventricular asymmetry on CT: how much asymmetry is representing pathology? Surg Radiol Anat 2008;30:249-55 CrossRef Medline

42. Trimarchi F, Bramanti P, Marino S, et al. MRI 3D lateral cerebral ventricles in living humans: morphological and morphometrical age-, gender-related preliminary study. Anat Sci Int 2013;88:61-69 CrossRef Medline

43. Zipursky RB, Lim KO, Pfefferbaum A. Volumetric assessment of cerebral asymmetry from CT scans. Psychiatry Res 1990;35:71-89 CrossRef Medline

44. Ichihashi K, Ino M, Eguchi Y, et al. Difference between left and right lateral ventricular sizes in neonates. Early Hum Dev 2002; 68:55-64 CrossRef Medline

45. $\mathrm{Lu} \mathrm{Z,} \mathrm{He} \mathrm{J,} \mathrm{Yu} \mathrm{Y,} \mathrm{et} \mathrm{al.} \mathrm{Measurement} \mathrm{of} \mathrm{lateral} \mathrm{ventricle} \mathrm{volume} \mathrm{of}$ normal infant based on magnetic resonance imaging. Chinese Neurosurg Journal 2019;5 CrossRef

46. Brouwer MJ, de Vries LS, Groenendaal F, et al. New reference values for the neonatal cerebral ventricles. Radiology 2012;262:224-33 CrossRef Medline

47. Allen JS, Damasio H, Grabowski TJ. Normal neuroanatomical variation in the human brain: an MRI-volumetric study. Am J Phys Anthropol 2002;118:341-58 CrossRef Medline

48. Tubbs RS, Shoja M, Loukas M. Bergman's Comprehensive Encyclopedia of Human Anatomic Variation. Hoboken: Wiley Blackwell; 2016: 943-53

49. Erdogan AR, Dane S, Aydin MD, et al. Sex and handedness differences in size of cerebral ventricles of normal subjects. Int J Neurosci 2004;114:67-73 CrossRef Medline
50. McRae DL, Branch CL, Milner B. The occipital horns and cerebral dominance. Neurology 1968;18(1 Pt 1):95-98 Medline

51. Paquette N, Shi J, Wang Y, et al. Ventricular shape and relative position abnormalities in preterm neonates. Neuroimage Clin 2017;15: 483-43 CrossRef Medline

52. Torkildsen $\mathrm{A}$. The gross anatomy of the lateral ventricles. J Anat 1934;68:480-91 Medline

53. Shen EY, Huang FY. Sonographic findings of ventricular asymmetry in neonatal brain. Arch Dis Child 1989;64:730-44 CrossRef Medline

54. Vandewalle G, Beuls E, Vanormelingen L, et al. Accessory intraventricular prominence of the occipital horn of the lateral ventricle. $J$ Neurosurg 2003;99:151-55 Medline

55. Bronen RA, Cheung G. MRI of the temporal lobe: normal variations, with special reference toward epilepsy. Magn Reson Imaging 1991;9:501-07 CrossRef Medline

56. Sadan S, Malinger G, Schweiger A, et al. Neuropsychological outcome of children with asymmetric ventricles or unilateral mild ventriculomegaly identified in utero. BJOG 2007;114:596-602 CrossRef Medline

57. Cha S, George AE. How much asymmetry should be considered normal variation or within normal range in asymmetrical frontal horns of the lateral ventricles noted during CT brains scans without evidence of midline shift or any other significant lesion? AJR Am J Roentgenol 2002;178:240 CrossRef Medline

58. Achiron R, Yagel S, Rotstein Z, et al. Cerebral lateral ventricular asymmetry: is this a normal ultrasonographic finding in the fetal brain? Obstet Gynecol 1997;89:233-37 CrossRef Medline

59. Meyer R, Bar-Yosef O, Barzilay E, et al. Neurodevelopmental outcome of fetal isolated ventricular asymmetry without dilation: a cohort study. Ultrasound Obstet Gynecol 2018;52:467-72 CrossRef Medline

60. Pfeiffer G, Friede RL. Unilateral hydrocephalus from early developmental occlusion of one foramen of Monro. Acta Neuropathol 1984; 64:75-77 CrossRef Medline

61. Lee JK, Wu J, Bullen J, et al. Association of cavum septum pellucidum and cavum vergae with cognition, mood, and brain volumes in professional fighters. JAMA Neurol 2019 Sep 9. [Epub ahead of print] CrossRef Medline

62. Filipovic B, Prostran M, Ilankovic N, et al. Predictive potential of cavum septi pellucidi (CSP) in schizophrenics, alcoholics and persons with past head trauma. Eur Arch Psychiatry Clin Neurosci 2004;254:228-30 CrossRef Medline

63. Hosseinzadeh K, Luo J, Borhani A, et al. Non-visualisation of cavum septi pellucidi: implication in prenatal diagnosis? Insights Imaging 2013;4:357-67 CrossRef Medline

64. Gray H. Anatomy of the Human Body. New York: Lea and Fibiger; 1918: plate 744

65. Gray H. Anatomy of the Human Body. New York: Lea and Fibiger; 1918: plate 738 